\author{
Amilton J. V. Arruda \\ Paulo Cesar Machado Ferroli \\ Lisiane Ilha Librelotto
}

(organizadores)

\title{
Série [designCONTEXTO]
}

Ensaios sobre Design, Cultura e Tecnologia

Design, Artefatos e Sistema Sustentável Arruda I Ferroli I Librelotto 
Série [designCONTEXTO] Ensaios sobre Design, Cultura e Tecnologia

Design, Artefatos e Sistema Sustentável

๑ 2018 Amilton Arruda; Paulo Cesar Machado Ferroli; Lisiane Ilha Librelotto (organizadores)

Editora Edgard Blücher Ltda.

Projeto gráfico e editorial

Juliana Carvalho | Erika Simona | Amilton Arruda

\section{Capa}

Leandro Cunha

\section{Comitê editorial}

Jonatas Eliakim

Amilton J. V. Arruda

\section{Revisão dos textos}

Editora Blucher

\section{Comitê científico}

Ph.D. Aguinaldo dos Santos - UFPR

Ph.D Amilton José Vieira de Arruda - UFPE

Dr. Caio Adorno Vassão - FAAP

Ph.D Carlo Franzato - UNISINOS

Dr. Célio Teodorico dos Santos - PPGD/UDESC

Dr. Danilo Émmerson N. Silva - CAA/UFPE

Dr. Eugenio Andrés Díaz Merino - PPGD -UFSC Mc.S. Fabrico Vanden Broeck - UAM Mexico

Dra. Germana G. de Araújo - UFSE

Dra. Heloisa Dallari Chypriades - FAAP
Dr. Itamar Ferreira da Silva - PPGD-UFCG

Dr. João de Souza Leite - PUC-RJ/ESDI-UERJ

Esp. Jorge Montana Cuellar - Ridiseño, Colômbia

Dr. Luis Carlos Paschoarelli - PPGD/Unesp

Dra. Lucy Niemeyer - UNIDCOM/IADE, Portugal

M.Sc. Marcelo J. O. Farias - IED-SP/FAAP

Ph.D. Marcelo M. Soares - UFPE

Dr. Paulo Cesar M. Ferroli - UFSC

Ph.D. Rui Miguel Ferreira Roda - EAD Lisboa

Dr. Yván Alexander Mendívez Espinoza - UCV Peru

\section{Blucher}

Rua Pedroso Alvarenga, 1245, $4^{\circ}$ andar

04531-934 - São Paulo - SP - Brasil

Tel.: $55113078-5366$

contato@blucher.com.br

www.blucher.com.br

Segundo Novo Acordo Ortográfico, conforme 5. ed. do Vocabulário Ortográfico da Língua Portuguesa, Academia Brasileira de Letras, março de 2009.

É proibida a reprodução total ou parcial por quaisquer meios, sem autorização escrita da editora.

Todos os direitos reservados pela Editora Edgard Blücher Ltda.
Dados Internacionais de Catalogação na Publicação (CIP) Angélica llacqua CRB-8/7057

Design, artefatos e sistema sustentável / organização de Amilton J.V. Arruda, Paulo Cesar Machado Ferroli, Lisiane Ilha Librelotto. -- São Paulo : Blucher, 2018.

360 p.: il. color.

([designcontexto]: Ensaios sobre Design, Cultura e Tecnologia)

\section{Bibliografia}

ISBN 978-85-8039-298-2 (e-book)

ISBN 978-85-8039-297-5(impresso)

1. Desenho industrial 2. Produtos - Desenvolvimento

3. Ecodesign 4. Sustentabilidade I. Arruda, Amilton J.V. II. Ferroli, Paulo Cesar Machado III. Librelotto, Lisiane Ilha IV. Série.

17-1826

CDD 745.4 


\section{CONTEÚDO}

05 Apresentação

\section{Seção \\ FUNDAMENTOS, ASPECTOS METODOLÓGICOS \\ E NOVOS CENÁRIOS PARA SUSTENTABILIDADE}

9 Design e emoção: conceitos fundamentais

Rodrigo Balestra Ferreira de Paiva

35 Projetos de pesquisa e desenvolvimento em design, sustentabilidade e inovação: bases teóricas para a contribuição do design

Cláudio Pereira de Sampaio, Suzana Barreto Martins

59 Sustentabilidade, desenvolvimento e inovação no século 21: demandas para o design de materiais avançados

Debora Barauna, Dalton Luiz Razera

87 Por uma estética voltada à sustentabilidade: estudos para configuração de novos artefatos ecologicamente orientados

Thamyres Oliveira Clementino, Amilton José Vieira de Arruda

107 Do design de produto às inovações sociais como resposta às causas diretas e indiretas dos impactos ambientais e sociais

Liliane Iten Chaves

129 Cenários de sustentabilidade e bem-estar para o design estratégico de um sistema produto-serviço de casas pré-fabricadas

Julia Weinschenck, Carlo Franzato

153 A metodologia de projeto de Zaha Hadid

Guilherme Gasques Rodrigues, Cláudio Silveira Amaral

167 Projetos de conclusão de curso de design com ênfase no eco design Ana Veronica Pazmino

\section{Seção \\ ASPECTOS DO DESIGN DE MATERIAIS, DESIGN DE PRODUTOS E DESIGN DE TERRITÓRIO}

189 Materiais e sustentabilidade: aplicações do bambu em arquitetura, design e engenharia

Lisiane Ilha Librelotto, Paulo Cesar Machado Ferroli 
213 Estratégias de projeto para a sustentabilidade: a modularidade no mobiliário.

André Midões, Mariana Vieira de Andrade, Cristiane Aun Bertoldi

229 A transformação dos resíduos sólidos da construção civil a partir do design estratégico

Laura Caroline Machado da Silva, Karine de Mello Freire

$2 \mathbf{4 7}$ Conhecimento indígena e processos para o desenvolvimento de produtos de design sustentável com Cana-flecha

(Gynerium Sagittatum)

Pedro Arturo Martínez Osorio, Paula Da Cruz Landim, Tomás Queiroz Ferreira Barata

267 Desenvolvimento de livro infantil com enfoque na reutilização e na reciclagem da embalagem cartonada longa vida Eliana Paula Calegari, Hilton Fagundes, Jussara Smidt Porto, Mariana Schmidt, Luis Henrique A. Cândido

287 Design e experimentação em bambu: desenvolvimento de uma linha de óculos de sol sustentável Giulianna de Moraes Godinho, Tomás Queiroz Ferreira Barata, Marco Antônio dos Reis Pereira

301 Design e cultura material em Minas Gerais - cultura, artesanato e patrimônio como fontes de inspiração para o design contemporâneo Rita de Castro Engler, Marilia de Fátima Dutra de Ávila Carvalho, Nadja Maria Mourão

317 Relato da experiência de valorização da agricultura familiar no norte do estado de Santa Catarina, por meio da gestão de design Giselle Schmidt Alves Díaz Merino, Giancarlo Philippi Zacchi, Adriana Tomazi Alves; Dione Nery Cavalcantid Benevenutti, Eugenio Andrés Díaz Merino

333 Design Sustentável aplicado ao projeto de produtos assistivos (próteses) fabricados com biocompósitos João Victor Gomes dos Santos, Marco Antonio dos Reis Pereira, Fausto Orsi Medola, Luis Carlos Paschoarelli

351 Bioarquitetura: Sistemas produtivos de mínimo impacto ambiental aplicados ao planejamento de habitações em áreas de risco Juliana Lima e Ingrid Braga 


\section{APRESENTAÇÃO}

Seguindo a trajetória iniciada com os dois primeiros volumes desta coleção: "Design \& Complexidade" e "Design \& Inovação Social", este livro apresenta uma série de capítulos escritos por pesquisadores de todo o país, que em comum buscam o entendimento da correlação existente entre o design e a sustentabilidade. 0 volume "Design, Artefatos e Sistemas Sustentáveis" representa o ápice de uma parceria entre os organizadores desta obra iniciada no evento ENSUS 2016. Através da convergência de ideias e pesquisas, autores e organizadores estreitam os laços, sobrepujando a distância geográfica que separa nossas instituições, mostrando que a interdisciplinaridade pode acontecer à distância.

O conceito de interdisciplinaridade ainda não é consenso na discussão epistemológica. Entretanto, diante do atual contexto das teorias do conhecimento com o questionamento dos discursos hegemônicos, a necessidade de consenso também está posta em crise. Dentre as diferentes correntes de conhecimento que balizam a interdisciplinaridade, seja a da filosofia do sujeito (aquela de viés idealista, que valoriza o sujeito em relação ao objeto de estudo e de visão a-histórica) e a do marxismo dialético (que insere a produção interdisciplinar nos moldes do modo de produção ao longo da história), pode-se apontar algumas possibilidades teóricas e práticas que têm sido incorporadas e que norteiam a produção dos pesquisadores inseridos nesta publicação.

A interdisciplinaridade não busca a superação da disciplina em si, pois a especialização permite superar o olhar genérico e superficial que muitos acólitos da visão holística pretendem como dominante e suficiente. De certo modo, a "horizontalização da verticalidade e a verticalização da horizontalidade" aponta para a superação dos extremos. Reside nesta publicação a possibilidade de cada área e cada especialista expor e submeter não só aos pares, mas aos "primos" (como dito por Siepierski, 1998) suas ideias, teorias e metodologias. E, desta exposição, que muitas vezes não é recebida com harmonia pelas outras disciplinas, pode surgir um conflito criativo e inovador em relação às especificidades. Tal conflito não significa a impossibilidade do diálogo, mas sim o debate de ideias antagônicas que se apresentam no fazer científico.

Os fenômenos relativos à sustentabilidade não são entendidos nem enfrentados por metodologias únicas, nem por profissionais específicos de um campo de conhecimento, mas seu enfrentamento acontece por meio da multidisciplinaridade e interdisciplinaridade. Desta forma, uma nova ciência surge capaz de congregar conhecimentos para resolver antigos problemas: a ciência da sustentabilidade.

As publicações aqui reunidas perpassam uma diversidade de abordagens, já que a sustentabilidade exige que suas metodologias específicas tenham interfaces com as novas mídias de representação e análise dos fenômenos ambientais, sociais e econômicos no emprego de materiais alternativos como o bambu, em novas estratégias de projeto, no reaproveitamento de resíduos, na integração de conteúdos culturais na proposição de novos saberes, na bioarquitetura, na agricultura.

De norte a sul do Brasil, passo a passo, estamos formando uma rede de pesquisadores que reúnem objetivos comuns e são dotados de saberes 
complementares que possibilitam esta visão interdisciplinar. 0 tema deste volume conduz em geral a uma redução forçada e limitante, dada à complexidade envolvida. A seleção dos capítulos que constituem a presente obra exemplifica isso, pois tratam de uma parte da problemática que, desagregada do todo, toma dimensões maiores. A cada novo projeto percebe-se que a questão da sustentabilidade não pode ser tratada de forma convencional. As variáveis de contorno que são tão usadas em pesquisas no intuito de delimitar a problemática e tornar possível atingir o objetivo proposto, perde um pouco do sentido quando se trabalha com uma visão global, onde eliminar o resíduo de um país pode significar aumentar o impacto em outro ponto do globo.

A UNEP (United Nations Environmental Programme) listou recentemente doze grandes problemas ambientais que mais preocupavam os pesquisadores, administradores, gerentes e governantes. Foram assim elencados: (1) crescimento demográfico, (2) urbanização acelerada, (3) desmatamento, (4) poluição marinha, (5) poluição do ar e do solo, (6) poluição e eutroficação de águas, (7) perda de diversidade genética, (8) efeitos de grandes obras civis, (9) alteração global do clima, (10) energia, (11) agricultura, e (12) saneamento básico assim como a AGENDA 2030 lista 17 novos ODS (Objetivos para o Desenvolvimento Sustentável). Tais objetivos, para serem alcançados, requerem o esforço conjunto e direcionado de uma série de disciplinas.

A leitura atenta dos capítulos deste livro integra alguns dos problemas presentes na sustentabilidade de forma mais direta e, outros indiretamente. Como medir a abrangência ou a urgência de cada um deles separadamente? Nunca na história da humanidade um tema exigiu tanto de algo que está em falta na academia: a humildade intelectual. Humildade não no sentido do desconhecimento, da falta de preparo, do conformismo ou amadorismo. Humildade no sentido de conhecermos nossas limitações para que possamos trabalhar em prol de nosso futuro e do entendimento de que não podemos sozinhos alcançar todas as facetas deste complexo problema.

A percepção urgente de que a Terra é uma só e a natureza, o meio-ambiente e todos os ecossistemas que a constituem não seguem a mesma lógica fragmentada das questões humanas de política, fronteiras geográficas entre países, disputas por recursos e riquezas, etc. As ações predatórias e nocivas que acontecem em um ponto do globo terrestre afetam toda a humanidade, da mesma forma que as ações benéficas.

Portanto, independente de nossa vontade, somente podemos tratar parte do problema a partir de um olhar direcionado, sem esquecer sua integração no todo constituído por inúmeras partes, adquirimos a consciência de que esse "todo" é menor que a soma de suas partes. Sobretudo, devemos recordar que este todo é indissociável.

A iniciativa do prof. Amilton Arruda de agregar os diversos temas recorrentes ao design demonstra tal realidade. Lamentavelmente ouvimos muitas pessoas, dentre elas pesquisadores, que não conseguem ver que a sustentabilidade está em tudo. Ela se relaciona com a parte estética do design, pois há de se ter consciência de que pigmentos, texturas, formatos, promoverão ações fabris e produtivas que irão impactar sobremaneira no consumo de matéria-prima, de energia, de água, na geração de resíduos sólidos, líquidos e gasosos, e assim por diante. 
Separar a ergonomia da sustentabilidade demonstra uma falta de visão do todo que herdamos dos anos 1970, quando tudo o que se falava sobre sustentabilidade foi resumido na UNCHE 72, em Estocolmo. Promover o conforto e a segurança de uso de um produto amplia o ciclo de vida, atualizar a antropometria e a biomecânica para os padrões modernos promove a universalização dos produtos, promovendo geração de renda e desenvolvimento social e econômico para áreas carentes.

Esse livro foi dividido em duas partes. Na primeira, denominada "Fundamentos, Aspectos Metodológicos e Novos Cenários para a Sustentabilidade" foram reunidas oito abordagens relevantes especialmente para quem busca o aprofundamento conceitual dos pilares da sustentabilidade. Além do texto propriamente dito, as referências bibliográficas relacionadas pelos autores convidam os leitores ao aprofundamento das questões essenciais para o entendimento da interdisciplinaridade que a sustentabilidade exige.

A sessão seguinte, de título "Aspectos do Design de Materiais, Design de Produtos e Design de Territórios" apresenta mais 10 capítulos, com ênfase nas aplicações, que dependendo da área de interesse do leitor, complementarão o que foi abordado nos capítulos anteriores. A diversidade de temas e de origem dos pesquisadores selecionados demonstra uma tendência nacional onde a experimentação de novos materiais buscando alternativas menos prejudiciais ao meio ambiente encontra aplicações em todas as áreas, como no design de produtos e na arquitetura.

Seis dos capítulos são estudos mais elaborados de artigos previamente apresentados no ENSUS 2017 - V Encontro de Sustentabilidade em Projeto. Este evento objetiva a convergência dos estudos de sustentabilidade projetual reunindo durante três dias, pesquisadores nacionais e estrangeiros, nas áreas de arquitetura, design e engenharias e esta publicação é uma das respostas fornecidas pela rede de parcerias tecida pelo evento frente às dificuldades acadêmicas e financeiras enfrentadas pelos pesquisadores brasileiros, muitos dos quais convivem com a escassez de recursos que inibem ou até mesmo inviabilizam a compra de materiais, participação em congressos e eventos internacionais, contratação de mão de obra de apoio, etc. além da multiplicação de tarefas que sobrecarregam a vida acadêmica.

Assim, do pouco de nossa contribuição, temos a certeza que em conjunto somos mais fortes. Esperamos que tenham uma boa leitura, para que vocês sejam novos elos desta rede e multiplicadores em novas redes que se constituam. 
